\title{
ANÁLISE DE ERROS NO CONCEITO DE FUNÇÃO: UMA POSSIBILIDADE DE APRENDIZAGEM
}

\author{
Teresa Cristina Etcheverria \\ Universidade Federal de Sergipe \\ tetcheverria@gmail.com \\ Wagner Ferreira Santos \\ Universidade Federal de Sergipe \\ wagnerf@ufs.br
}

\section{Resumo}

Este artigo, oriundo de uma pesquisa em andamento, se propõe a discutir a produção escrita de estudantes do $1^{\circ}$ ano do Ensino Médio em atividades que envolvem o conceito de função. $\mathrm{O}$ estudo está fundamentado na ideia de que a análise da produção escrita dos alunos também pode ser vista como uma metodologia de ensino (CURY, 2008). A coleta de dados foi realizada por meio de atividades aplicadas aos alunos do $1^{\circ}$ ano do Ensino Médio de uma escola do interior do estado de Sergipe. Neste trabalho são discutidos apenas os dados obtidos na aplicação das atividades voltadas para o conceito de função. Os resultados revelam que poucos estudantes conseguiram destacar os erros na análise da produção escrita de colegas e que alguns reconhecem que numa função todo elemento do domínio deve corresponder a um elemento do contradomínio, e apenas um. Além disso, os dados sinalizam que esses discentes apresentam dificuldades no uso correto da linguagem matemática.

Palavras-chave: Análise de Erros. Metodologia de Ensino. Funções.

\begin{abstract}
This article, from a research in progress, it is proposed to discuss the written production of first year students of secundary school in activities that envolve the concept of function. The study is based on the idea that analisys of written production of pupils could be seen as a teaching methodology (CURY, 2008). The datas were colected by mean of activities which were aplied to first year students of secundary school in countryside village of Sergipe state. In this work are argued only the datas from aplication of activities about the concept of function. The results shows that few students could highlight the errors on analisys of written production of their classmates and that some recognize that in a function all element of domain must to correspond to an element of codomain, and only one. Besides, the datas show this pupils have difficulties on right use of mathematical language.
\end{abstract}

Keywords: Error Analysis. Teaching Methodology. Functions.

\section{INTRODUÇÃO}

Durante a realização de investigações com professoras dos anos iniciais do Ensino Fundamental do contexto em estudo, percebemos que as mesmas não analisavam as estratégias de resolução de seus alunos, fossem elas corretas ou incorretas. E, dessa forma, os procedimentos de resolução utilizados pelos estudantes, 
corretos ou incorretos, eram repetidos em situações análogas e se mantinham durante muito tempo.

Também, o acompanhamento realizado no trabalho desenvolvido pelos estagiários do curso de Licenciatura em Matemática nos oportunizou perceber que professores dos anos finais do Ensino Fundamental fazem a correção da produção escrita dos estudantes nas atividades avaliativas apenas atribuindo nota, sem analisar os erros cometidos pelos mesmos e sem, tampouco, oportunizar que eles façam essa análise, o que favorece a sistematização dos erros que cometem.

Essas práticas dos professores nos levaram a observar que as respostas dadas pelos estudantes às questões propostas nos instrumentos avaliativos, muitas vezes, não são consideradas como reveladoras de um conhecimento. Isso está presente tanto nas situações às quais o professor atribui nota zero a uma resposta que apresenta somente o resultado de um cálculo ou expressão matemática, quanto nas situações em que o estudante faz uso de um procedimento correto, mas realiza algum cálculo errado, o que faz com que o resultado final esteja errado. Essa atitude revela que para alguns professores o erro apenas indica um mau desempenho do aluno. Para Pinto (2000), ao pensar assim, o professor está somente valorizando o resultado final e isso "é decepcionante, pois reflete um fracasso que não é só do aluno, mas também do professor" (PINTO, 2000, p.139). O autor defende a ideia de que o erro, quando observado com maior rigor, pode fornecer elementos que possibilitem ao professor refletir sobre sua maneira de ensinar, o que lhe permite criar novos direcionamentos para suas ações pedagógicas.

Por acreditar que as respostas dos estudantes podem oportunizar uma prática educativa que possibilita aprendizagens tanto aos estudantes quanto aos professores, redirecionando e reorientando os modos de aprender e ensinar em sala de aula, neste artigo buscamos refletir sobre a produção escrita de estudantes do $1^{\circ}$ ano do Ensino Médio na resolução de exercícios envolvendo o conceito de Função.

Os dados coletados fazem parte de uma pesquisa em andamento, realizada pelos autores, na qual se busca investigar quais contribuições o uso da análise de erros traz para o ensino e o aprendizado da Matemática em turmas da Educação Básica.

Para isso, dividimos o texto em quatro partes: a primeira apresenta o embasamento teórico da pesquisa; a segunda parte abrange a descrição dos procedimentos efetuados e dos critérios de análise e, ainda, identifica os sujeitos 
envolvidos; na penúltima parte abordamos a análise dos resultados. Para finalizar, apresentamos algumas considerações que sintetizam a análise e apontamos alguns encaminhamentos.

\section{ANÁLISE DE ERROS COMO METODOLOGIA DE ENSINO}

Os registros escritos feitos pelos estudantes na resolução de uma atividade marcam o caminho escolhido por ele, revelando estratégias e procedimentos utilizados. A análise desses registros pode oportunizar a compreensão das dificuldades presentes na atividade matemática dos discentes.

Estudos realizados sobre os erros cometidos por estudantes revelam que a análise da produção escrita dos alunos, em qualquer nível de ensino, pode ser considerada tanto sob o ponto de vista da investigação quanto do ensino (CURY, 2008). A autora acredita que a análise dos erros cometidos pelos alunos pode ser considerada uma metodologia de ensino quando oportuniza que eles questionem suas próprias soluções e, por meio desses questionamentos, construam conhecimentos.

Durante a correção de uma prova ou teste, na maioria das vezes, o professor olha para o acerto do aluno como algo que ele sabe ou que aprendeu, e para o erro como algo que ele não sabe ou que não aprendeu. Entretanto, as produções escritas do estudante, "tem características que permitem detectar as maneiras como o aluno pensa e, mesmo, que influências ele traz de sua aprendizagem anterior, formal ou informal" (CURY, 2008). Isto significa dizer que ao escrever sua resposta, mesmo que incorreta, o aluno está revelando um conhecimento que possui.

Para ajudar o aluno na superação desse saber equivocado é necessário desestabilizar suas certezas, levando-o a se questionar sobre sua resposta. Essa proposta tem origem nas ideias de Borasi (1996), na qual a autora sugere que o erro do estudante seja utilizado para que ele se questione sobre aquele resultado. Ao analisar um resultado incorreto o discente tem a possibilidade de expressar e investigar suas dúvidas. Também, segundo Azevedo (2009) esse procedimento possibilita ao professor acompanhar o processo de construção do conhecimento do aluno.

Silva e Buriasco (2005) afirmam que utilizar a avaliação dos estudantes como instrumento de investigação da aprendizagem pode contribuir no desenvolvimento dos alunos à medida que possibilita que eles identifiquem e compreendam seus erros, 
buscando superá-los. E, também, oportuniza ao professor uma reflexão sobre o planejamento, desenvolvimento e avaliação da ação docente.

Apesar do erro ainda ser considerado por muitos professores como revelador da incapacidade do aluno, Silva e Buriasco (2005) entendem que o professor deve conceber o erro como um meio de desenvolvimento e, por isso, se faz necessário que ele conheça e busque compreender os erros cometidos pelos alunos, pois os mesmos revelam as lacunas no aprendizado dos estudantes.

Da mesma forma, cabe ao professor oportunizar que os discentes identifiquem e reflitam sobre seus erros, buscando corrigi-los, ao refazerem o caminho de resolução escolhido. Quando a situação de erro serve ao aluno como meio de reflexão sobre o que ele pensa sobre determinado assunto, ela é considerada como possibilidade de aprendizado (SILVA E BURIASCO, 2005).

Vale destacar que ao se utilizar a análise da produção escrita apresentada pelos estudantes como resposta ao exercício ou tarefa, a mesma não deve ser mensurada, ou seja, a ela não deve ser atribuída um conceito ou uma nota. Numa investigação que busca reconhecer a análise de erros como metodologia de ensino, os erros cometidos pelos estudantes são vistos como subsídio para o planejamento de estratégias de ensino.

\section{METODOLOGIA}

Este trabalho trata de um estudo de natureza qualitativa, uma vez que se buscou compreender os erros presentes nas produções escritas dos estudantes em atividades que envolvem o conteúdo funções, de forma que essa compreensão e os meios de obtê-la pudessem ser reconstituídos (BOGDAN e BIKLEN, 1994). Para ilustrar a análise foram utilizados dados quantitativos.

A busca de compreensão das informações na produção escrita dos estudantes nos possibilitou olhar tanto para a produção escrita de cada um, considerando as características e as dificuldades apresentadas; quanto no todo, ao analisarmos a mesma questão de todos os alunos, verificando os pontos comuns e as regularidades presentes na produção escrita desse grupo de alunos. Esse processo nos permitiu inferir sobre os procedimentos e estratégias utilizados pelos estudantes.

Para compreender a questão abordada, tendo como foco o processo, fizemos 
encontros quinzenais com os professores participantes para oportunizar espaços de discussão sobre os erros cometidos pelos estudantes e ações docentes que pudessem contribuir na superação dos mesmos. Ou seja, a investigação dos erros dos discentes buscou possibilitar a compreensão e a transformação da prática docente dos professores.

Participaram desta etapa da pesquisa dois professores que ensinam Matemática em escolas públicas do Ensino Médio do estado de Sergipe com seus respectivos alunos e uma graduanda do curso de Licenciatura em Matemática.

Os encontros entre os professores do Ensino Médio, os pesquisadores e a graduanda ocorreram no Campus da Universidade, no período de Maio a Dezembro de 2015. Nos mesmos, primeiramente, foram realizadas discussões sobre o uso da análise de erros como método de investigação e ensino, com base nos textos de Cury (2008); Silva e Buriasco (2005) e Souza (2009). Também, foram elaboradas tarefas envolvendo os conceitos discutidos nas aulas de Matemática das turmas envolvidas, para serem aplicadas, sem o objetivo de atribuir nota, e recolhidas para realização da correção e análise dos erros cometidos pelos estudantes. O desenvolvimento das atividades com os discentes ocorreu na sala de aula de cada turma.

A correção da produção escrita apresentada pelos estudantes como resolução do exercício foi feita segundo as orientações de Cury (2008), separando as respostas em "totalmente correta"; "parcialmente correta" e "incorreta". Apesar do foco de investigação estar nos erros cometidos, como a meta estava no ensino e na aprendizagem, também as respostas corretas foram observadas para que fosse identificado o procedimento utilizado pelo estudante. As respostas com algum tipo de erro foram analisadas e os erros foram categorizados.

De posse dos dados coletados na análise, os dois professores, juntamente com a graduanda e os pesquisadores, buscavam elaborar atividades que visassem oportunizar aos estudantes a conscientização e superação dos erros cometidos. Na sequência, novamente os alunos foram avaliados e foi realizado o registro do novo desempenho.

Os instrumentos aplicados aos estudantes foram identificados por nós com a letra A (Aluno) seguida de um número de ordem $(1,2,3, \ldots)$; a letra $\mathrm{P}$ (Professor) seguida do número 1, pois neste estudo constam apenas as análises do Professor 1; e da letra T (Tarefa) seguida da identificação 1 ou 2 que indicam, respectivamente, resposta da tarefa 1 e resposta da tarefa 2. Neste artigo escolhemos discutir somente resultados dos alunos de $\mathrm{P} 1$ porque, comparando com os de $\mathrm{P} 2$, essa turma teve um maior número 
de respostas incorretas na tarefa que envolveu o conceito de função.

\section{ANÁLISE DE ALGUNS RESULTADOS}

O ensino do conceito de função foi o primeiro tópico discutido no grupo de pesquisa. Essa escolha levou em consideração dois aspectos: (i) era o conteúdo que estava sendo ensinado pelos professores; e (ii) a importância do mesmo no aprendizado matemático da disciplina de Cálculo 1, devido ao grande número de reprovações nessa disciplina no primeiro semestre do curso de Licenciatura em Matemática.

Após os professores abordarem o conteúdo com os alunos, foi aplicada a Tarefa 1 com o objetivo de coletar indícios que revelassem as noções relacionadas ao conceito de função aprendidas pelos discentes. A Tarefa 1 foi elaborada pelos dois professores juntamente com os coordenadores do projeto e a graduanda.

Tarefa 1: Responda as perguntas seguintes, analisando as figuras abaixo.

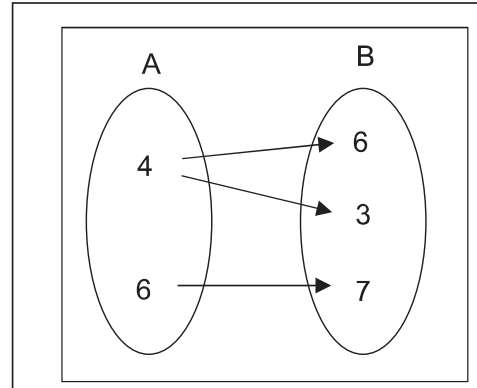

Figura 1

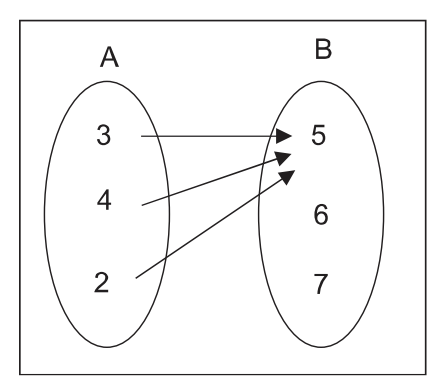

Figura 2

1. Quais das figuras acima representam uma função de A em B? Justifique sua resposta.

2. Escreva o domínio, o contradomínio e o conjunto imagem para cada função do item 1.

3. Represente no plano cartesiano a relação apresentada na figura 2.

4. Dos diagramas do item 1, quais representam uma função de B em A, quando invertemos

as flechas? Justifique sua resposta.

Apresentamos na Tabela 1 os resultados de desempenho de 16 estudantes do P1 na resolução da Tarefa T1 envolvendo o conceito de função.

Tabela 1: Desempenho dos alunos do P1 na T1

\begin{tabular}{ccccc}
\hline Questão & Correta & $\begin{array}{c}\text { Parcialmente } \\
\text { Correta }\end{array}$ & Incorreta & Branco \\
\hline $\mathbf{1}$ & 1 & 1 & 13 & 1 \\
\hline $\mathbf{2}$ & 4 & 1 & 10 & 1 \\
\hline $\mathbf{3}$ & 6 & 1 & 8 & 1 \\
\hline $\mathbf{4}$ & 9 & 0 & 6 & 1 \\
\hline
\end{tabular}

Fonte: Banco de dados dos autores 
Como observamos nos resultados da Tabela 1, a turma de P1 teve um desempenho baixo, pois o número de respostas corretas foi pequeno nas três primeiras questões. O pior desempenho foi na primeira pergunta, pois somente um estudante a resolveu corretamente, sinalizando que o conceito de função não foi compreendido pela turma ou, então, que os alunos não conseguem expressá-lo corretamente.

Tendo em vista a ideia de que uma reflexão detalhada sobre o erro do aluno possibilita ao professor a elaboração de novos direcionamentos para suas ações pedagógicas (PINTO, 2000), foi sugerido que P1 retomasse o conceito de função com a turma. Para tanto, P1, juntamente com os coordenadores da pesquisa e levando em conta os erros cometidos pelos estudantes, elaborou uma atividade não rotineira sobre o conceito de função. A atividade criada pelo grupo foi intitulada "Correspondências" e está descrita a seguir:

\begin{tabular}{|l} 
Atividade 1: Correspondências \\
Relação de A em B \\
Material: cartas com um número em cada lado (os números correspondem aos pares \\
ordenados de um diagrama), cada carta corresponde a um par ordenado e as cartas têm \\
cores diferentes de cada lado. \\
1. Pedir que um aluno retire uma carta e registre o par ordenado no quadro. Repetir o \\
processo para cada carta que esteja no envelope. \\
2. Pedir que um aluno represente os pares ordenados em diagramas. \\
3. Questionar se a relação representada no diagrama representa uma função. \\
4. Determinar o domínio e o contradomínio da relação. \\
5. Pedir que outro aluno represente no quadro a relação no plano cartesiano. \\
6. Questionar se quando tivermos uma relação de B em A, se a relação será uma função. \\
(Sugestão: Com base nos registros feitos, retomar desde a formação do par ordenado, \\
registrar tudo novamente, mas agora com os valores de B em A.)
\end{tabular}

Fonte: Atividade desenvolvida pelos autores

Após a realização da atividade "Correspondências", foi proposta a Tarefa T2 que consistiu em promover uma reflexão, por meio de duas respostas erradas dadas por dois colegas da turma, sobre o conceito de função. Nosso objetivo era o de investigar se após as novas explicações realizadas por P1 havia ocorrido alguma mudança na concepção dos estudantes sobre o conceito de função, o que em nosso entender seria revelado na análise feita nos erros dos colegas. 
Tarefa 2: Responda as perguntas seguintes, analisando as figuras abaixo.

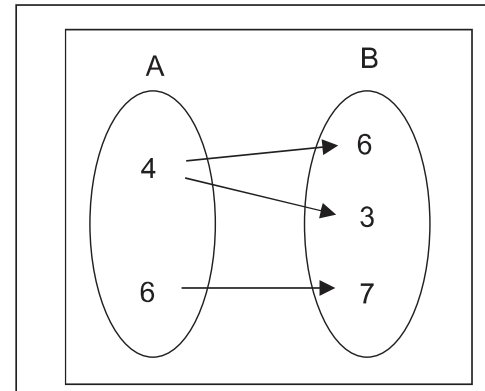

Figura 1

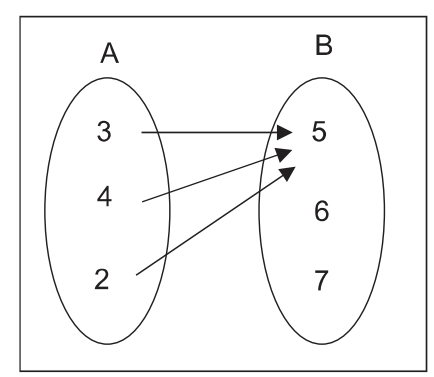

Figura 2

1. Quais das figuras acima representam uma função de A em B? Justifique sua resposta.

Ao observar os diagramas os estudantes deram as seguintes respostas:

1) A figura 1 não é conjunto porque o domínio não pode representar dois elementos.

2) A figura 2 não é uma função porque não pode sobrar elementos do lado B.

a) Analise as respostas apresentadas pelos estudantes e destaque os passos errados.

b) Escreve sua resolução para a questão 1.

$\mathrm{Na}$ Tabela 2 apresentamos os resultados gerais de 15 alunos da turma de P1 na Tarefa T2.

Tabela 2 - Resultados da turma de P1 na T2

\begin{tabular}{ccccc}
\hline Questão & Correta & $\begin{array}{c}\text { Parcialmente } \\
\text { Correta }\end{array}$ & Incorreta & Branco \\
\hline a.1 & 2 & 9 & 4 & - \\
\hline a.2 & 5 & 5 & 2 & 3 \\
\hline b & 8 & 1 & 6 & - \\
\hline \multicolumn{5}{r}{ Fonte: Banco de dados dos autores }
\end{tabular}

No item "a.1" estão os resultados referentes à resposta errada dada por um colega da turma. Esperávamos que nessa resposta os estudantes identificassem os seguintes erros: (i) a palavra "conjunto" foi usada no lugar da palavra "função"; (ii) o estudante suprimiu a palavra "elemento" antes da palavra "domínio"; (iii) o estudante utilizou a palavra representar no lugar da palavra associar. Como nenhum estudante identificou esses três erros, consideramos corretas as respostas nas quais os estudantes conseguiram identificar que houve a troca da palavra "função" pela palavra "conjunto" e que houve a supressão da palavra "elemento". Observa-se na Tabela 2 que somente dois estudantes identificaram corretamente esses erros. Contudo, mais da metade, nove estudantes, acertou parcialmente essa questão. Consideramos parcialmente correto se afirmou um dos dois argumentos corretos.

No item "a.2" estão os resultados referentes à outra resposta errada dada por um colega da turma. Neste item era esperado que o estudante afirmasse: (i) que era função de A em B; e (ii) que pode sobrar elementos no contradomínio B sem estar 
associado a elementos do domínio A. Nesse item se percebe que o desempenho dos alunos melhorou um pouco, mas ainda ficou abaixo da metade.

No item "b" consideramos corretas as respostas que afirmaram que a Figura 1 não representa uma função de $\mathrm{A}$ em $\mathrm{B}$, pois o elemento 4 , que pertence a $\mathrm{A}$, está associado a dois elementos de B (3 e 6) e que a figura 2 é uma função, pois cada elemento do conjunto A tem um único correspondente em B.

A Tabela 2 mostra um avanço no número de respostas corretas nesse item que retoma a resolução da Questão 1 da T1. Como pode ser observado na Tabela 1, da primeira vez somente um aluno acertou, depois da retomada da explicação pelo professor, na T2, 8 estudantes acertaram.

\section{Análise da produção escrita dos alunos}

Partindo do pressuposto de que a análise referente às produções escritas dos estudantes nos permite conhecer as aprendizagens desses discentes (CURY, 2008), na sequência, passamos a comentar as respostas dadas pelos alunos identificados por nós como A6, A7, A11, A12 e A13 nas Tarefas T1 e T2. A escolha desses alunos se deu pelo fato de que as respostas deles puderam ser categorizadas em dois grupos: no primeiro grupo, formado por A6, A7 e A12, a afirmação "a figura 1 não é conjunto porque o domínio não pode representar dois elementos" foi o padrão de resposta; no segundo grupo, formado por A11 e A13, a afirmação "a figura 2 não é função porque não pode sobrar componente no lado B", foi o padrão de resposta, como pode ser observado a seguir.

Na Figura 1 mostramos as respostas dadas pelos estudantes A6, A7 e A12 à Questão 1 da Tarefa 1.

Figura 1 - Resposta dada pelos alunos A6, A7 e A12, nesta ordem, à Questão 1 da Tarefa 1

1) Quais destas figuras representam uma função de $\mathrm{A}$ em $\mathrm{B}$ ? Justifique sua resposta.

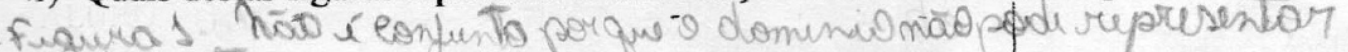
dois elemintos

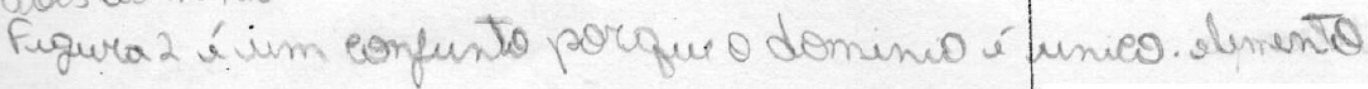

1) Quais destas figuras representam uma função de A em B? Justifique sua resposta.

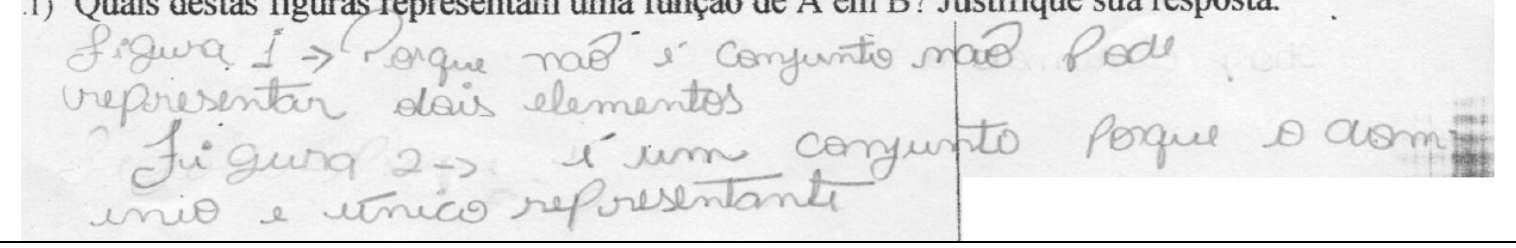

ReviSeM, Ano 2016, No. 1, p. $1-18$ 
1) Quais destas figuras representam uma função de $A$ em $B$ ? Justifique sua resposta.

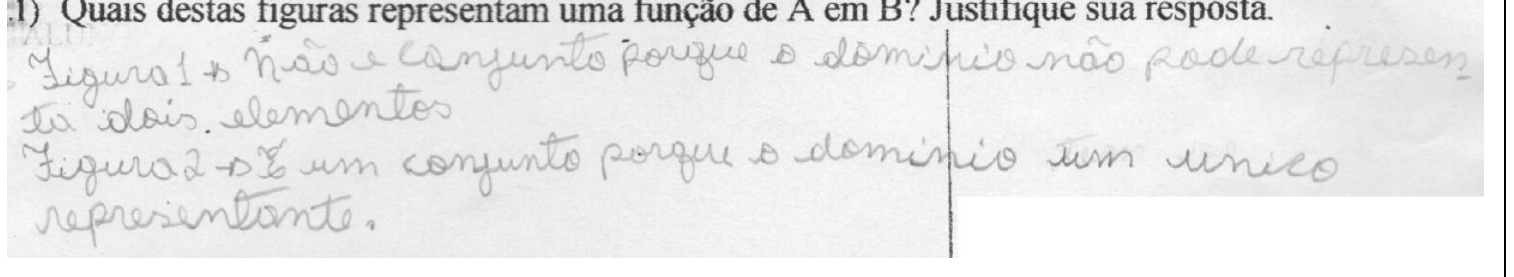

Fonte: Banco de dados dos autores

A Tarefa T1 pedia que os alunos classificassem e justificassem se duas relações, representadas em diagramas, eram ou não funções. Observa-se na Figura 1 que os alunos A6, A7 e A12 trocaram o termo "função" por "conjunto". É possível que isso tenha acontecido pelo motivo dos diagramas representarem conjuntos. Além disso, eles usaram a expressão "domínio" quando deveriam dizer "elementos do domínio", o que revela a utilização inadequada da linguagem matemática. As respostas revelam que esses estudantes compreenderam o conceito de função, mas ainda não conseguem expressá-lo numa linguagem matemática adequada.

Na Figura 2 mostramos as respostas dadas pelos estudantes A11 e A13 à Questão 1 da Tarefa 1.

Figura 2 - Resposta à tarefa T2 dos alunos A11 e A13

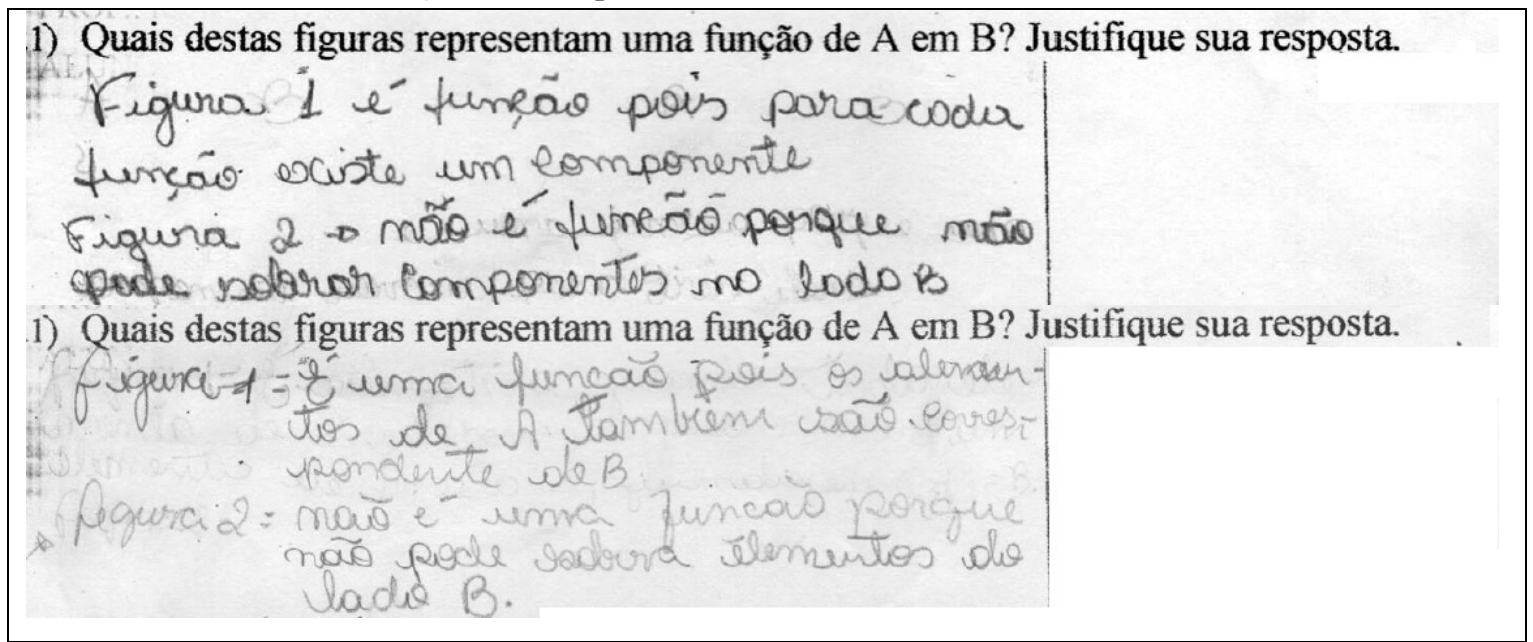

Fonte: Banco de dados dos autores

Nas respostas dos estudantes A11 e A13 observa-se que o termo "função" foi utilizado corretamente, porém eles classificaram incorretamente as relações ao afirmarem que a primeira relação representava uma função e a segunda não, o que revela que eles ainda não compreenderam o conceito de função.

Durante a discussão sobre os erros cometidos por esses estudantes, surgiram alguns questionamentos: Será que uma nova apresentação da tarefa, agora solicitando a 
identificação de erros cometidos por colegas, contribuiria no aprendizado do conceito de função? Será que esse olhar sobre o erro do colega os auxiliaria a identificar e corrigir seus próprios erros? Acreditando nessa ideia que também é defendida por Borasi (1996); Silva e Buriasco (2005), propusemos a Tarefa T2 na qual foi solicitado que os discentes identificassem os erros cometidos por seus colegas.

Para discutir os resultados dessa tarefa, a seguir apresentamos uma análise do desempenho de cada um dos estudantes, por grupo.

\section{O primeiro grupo de alunos (A6, A7 e A12)}

$\mathrm{Na}$ análise da produção escrita dos alunos do primeiro grupo, formado por A6, A7 e A12, buscamos olhar as respostas dos mesmos nas três situações diferentes: no primeiro retângulo a resposta que ele deu à Questão 1 da Tarefa 1; no segundo, a resposta que ele deu quando foi solicitado que analisasse as respostas de seus colegas e destacasse os erros (Tarefa 2); e no terceiro, a sua nova resolução para a Questão 1 (Tarefa 2).

Iniciamos pelo aluno identificado por A6.

Figura 3 - Respostas de A6 nas Tarefas T1 e T2

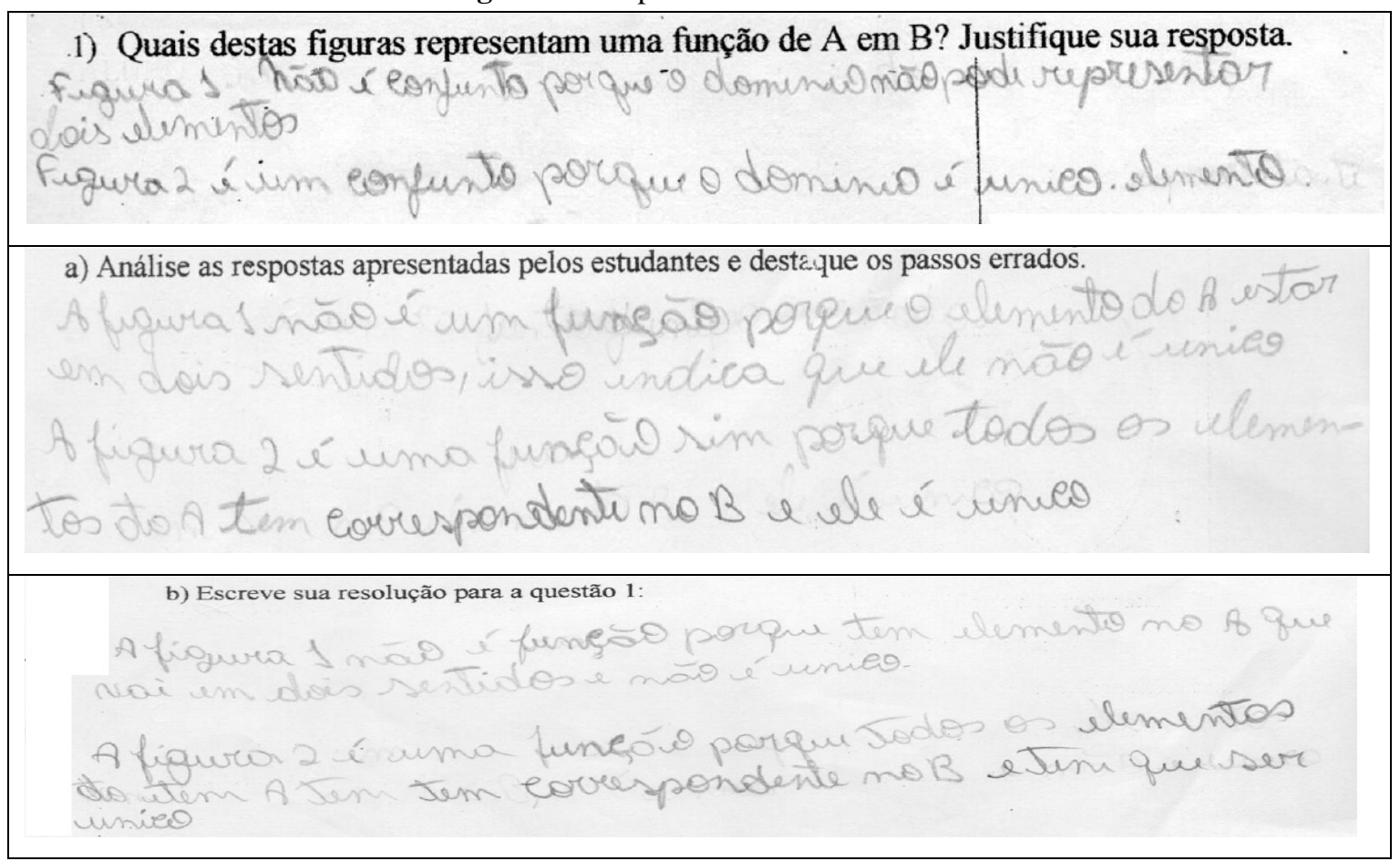

Fonte: Banco de dados dos autores

Podemos observar no primeiro retângulo da Figura 3 que o aluno A6 respondeu 
de forma incorreta a questão quando a respondeu pela primeira vez. Como já foi dito antes, ele trocou o termo "função" por "conjunto". No segundo retângulo podemos observar que ele não destacou os erros cometidos pelos colegas, em vez disso, escreveu a resposta que considerou estar correta. No terceiro retângulo está a nova resolução dele para a Questão 1. A primeira resposta, relacionada à primeira relação, identificada na atividade como Figura 1, revela que ele conseguiu corrigir os erros que cometeu quando resolveu a questão pela primeira vez, contudo cometeu um novo erro quando disse que "tem elemento de A que vai em dois sentidos", querendo se referir que existe um elemento de A que corresponde a dois elementos de B. A segunda resposta, relacionada à segunda relação ou Figura 2, evidencia que o trabalho desenvolvido pelo professor e o pensar sobre os erros do colega o ajudaram a expressar numa linguagem matemática mais clara, contudo ainda há um equívoco nessa frase, quanto à utilização do termo "item" no lugar de "conjunto".

O estudante A7 deu as seguintes respostas:

Figura 4 - Respostas do aluno A7 nas tarefas T1 e T2

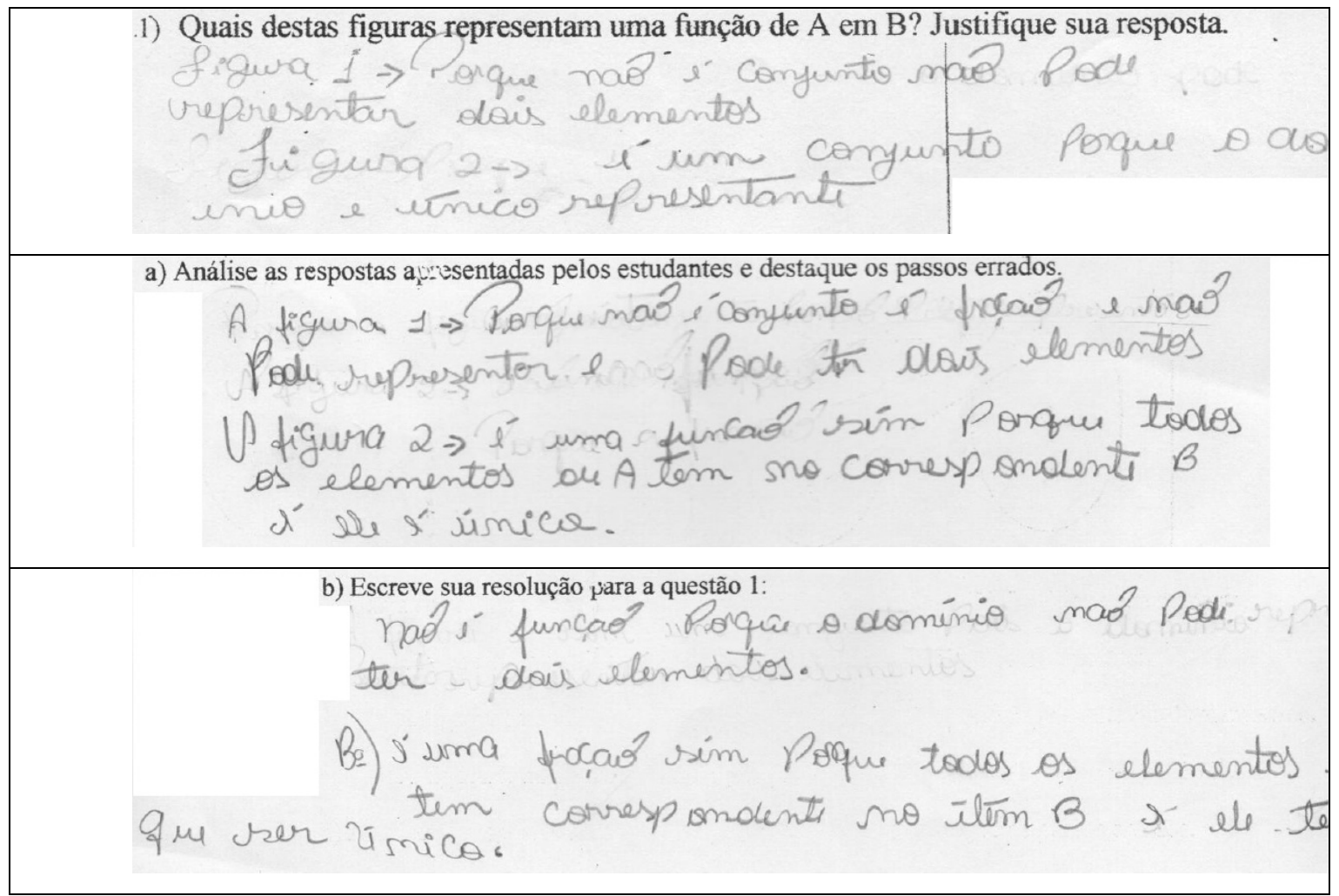

Fonte: Banco de dados dos autores

Podemos observar no primeiro retângulo da Figura 4 que o aluno A7 respondeu de forma incorreta a questão na tarefa T1 porque, assim como A6, também trocou o 
termo "função" por "conjunto". Na resposta do segundo retângulo, ele observa que o termo "conjunto" está mal-empregado, mas faz a substituição pelo termo "fração". É possível que tenha sido falta de atenção por conta da proximidade na grafia e no som das palavras "função" e "fração" e por ser mais comum o uso do termo "fração". E, a sua nova resolução para a Questão 1, revela que ele conseguiu perceber que o uso da palavra "conjunto" estava incorreto, porém, no item "b", cometeu um novo erro quando usou a palavra "fração" em vez de "função". Apesar disso, entendemos que o aluno A7 conseguiu avançar, pois evidencia compreender que "numa função todos os elementos do domínio têm correspondente no contradomínio, e este é único”.

As respostas dadas pelo estudante A12 foram as seguintes:

Figura 5 - Respostas do aluno A12 nas tarefas T1 e T2

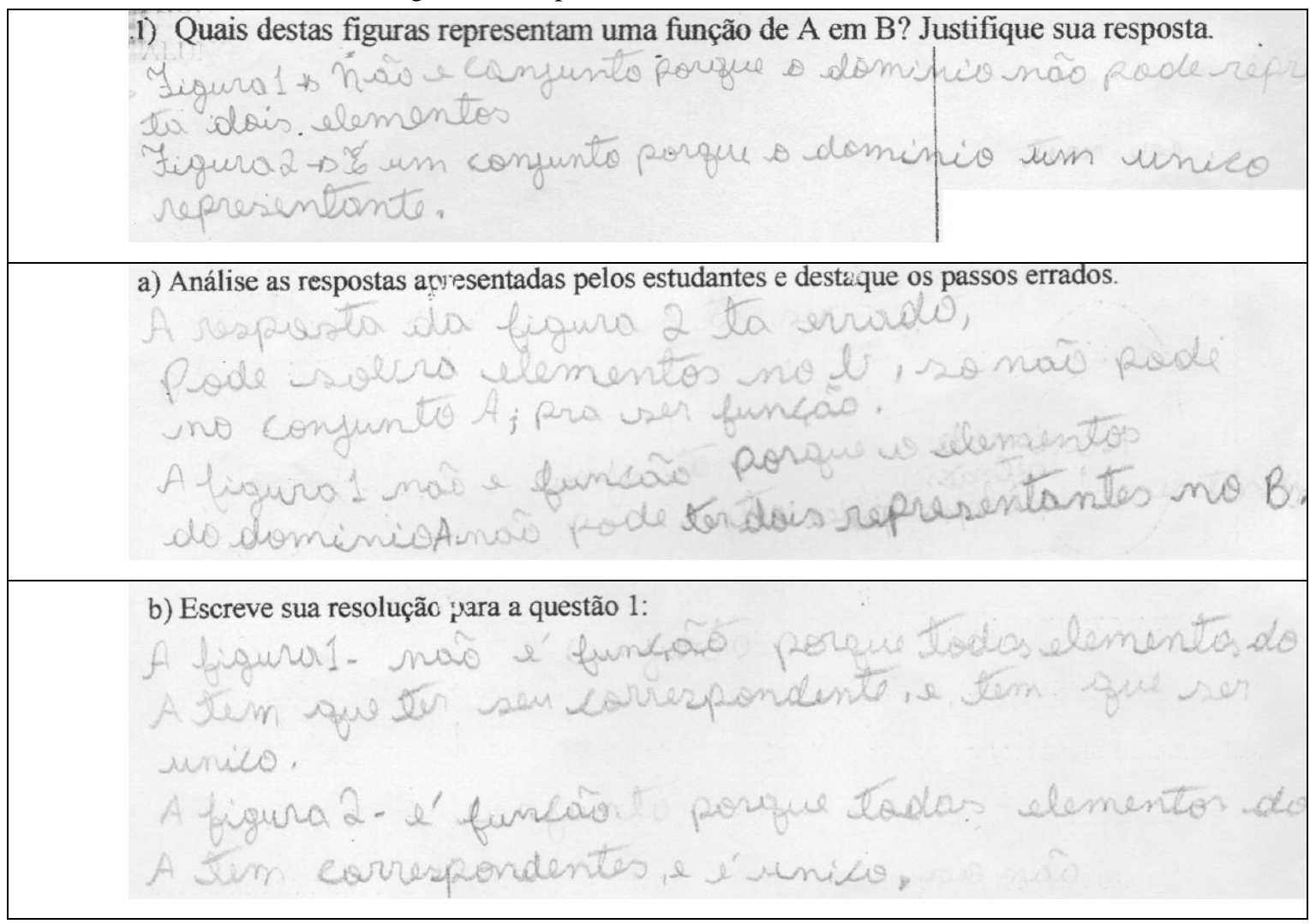

Fonte: Banco de dados dos autores

A produção escrita feita pelo estudante A12 na Questão 1, primeiro retângulo da Figura 5, nos mostra que ele compreendeu o conceito de função, mas como já foi dito antes, ele trocou o termo "função" por "conjunto" e também usou a palavra "domínio" para se referir a "elemento do domínio". No segundo retângulo podemos observar que ele identificou que as respostas de seus colegas estavam erradas, entretanto 
não identificou os erros. Na primeira frase, explica o que precisa para ser função e na segunda frase ele nota que a resposta dada para análise está errada e aponta que a justificativa não é válida, uma vez que, segundo suas próprias palavras, "pode sobrar elementos no B, só não pode no conjunto A". O mais importante é que fez as correções adequadas substituindo "conjunto" por "função" e que se referiu a "elemento do domínio" e não a "domínio". Na nova resolução dele para a Questão 1, terceiro retângulo da Figura 5, classificou corretamente cada uma das relações e justificou usando a linguagem matemática adequada.

As produções escritas dos estudantes desse grupo revelam que eles construíram uma concepção de que "numa função todo elementos do domínio têm correspondente no contradomínio, e este é único". Contudo, ainda não parecem conseguir adaptá-la para justificar porque alguma relação não é função, repetindo apenas o verbalismo da definição de função sem apontar qual condição não é satisfeita na situação. Além disso, alguns estudantes desse grupo ainda não conseguem expressar na linguagem matemática adequada suas concepções sobre o conceito de função, pois trocam o nome de alguns termos, tais como: "função" por "fração" e "conjunto" por "item".

\section{O segundo grupo de alunos (A11 e A13)}

A análise da produção escrita dos alunos do segundo grupo (A11 e A13) seguiu os critérios da análise dos estudantes do primeiro grupo. O segundo grupo de alunos apresentou erro na classificação das relações quanto elas serem função ou não.

Iniciamos pelo aluno identificado por A11.

Figura 6 - Respostas do aluno A11 nas tarefas T1 e T2

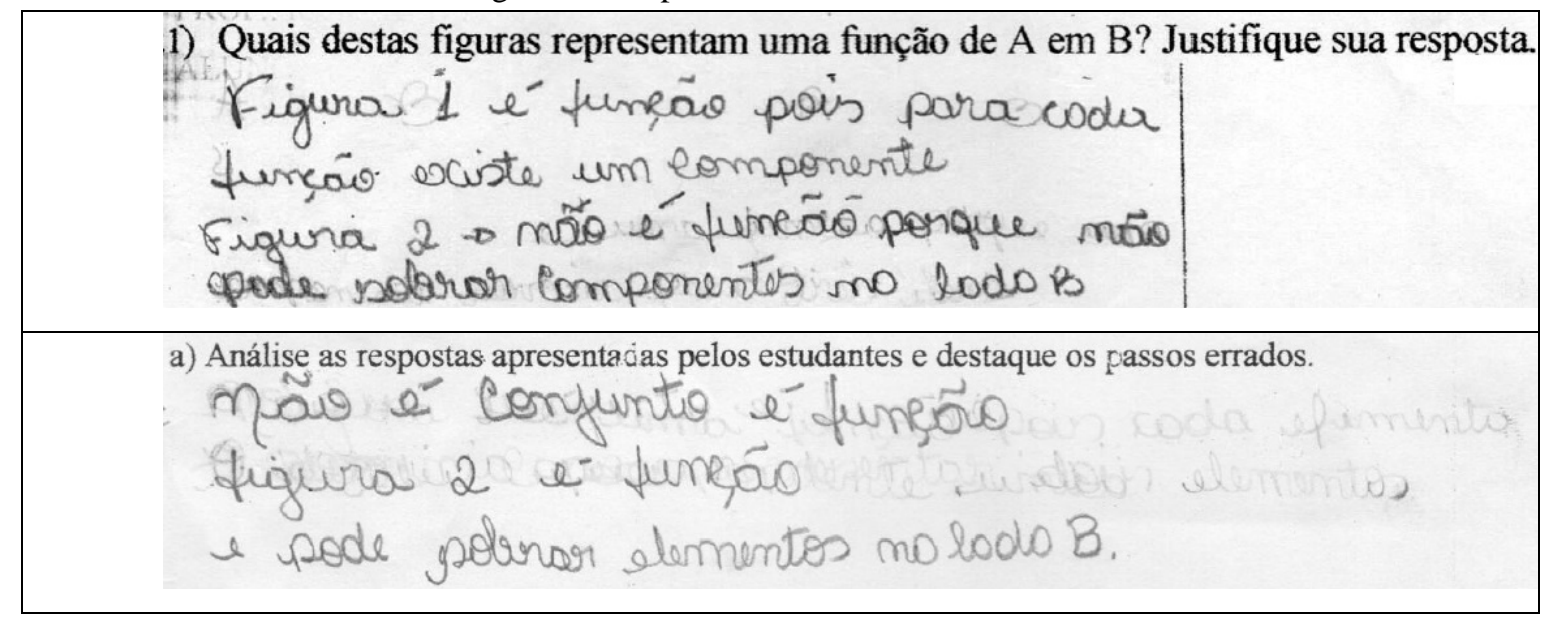


b) Escreve sua resolução para a Gquestão 1:

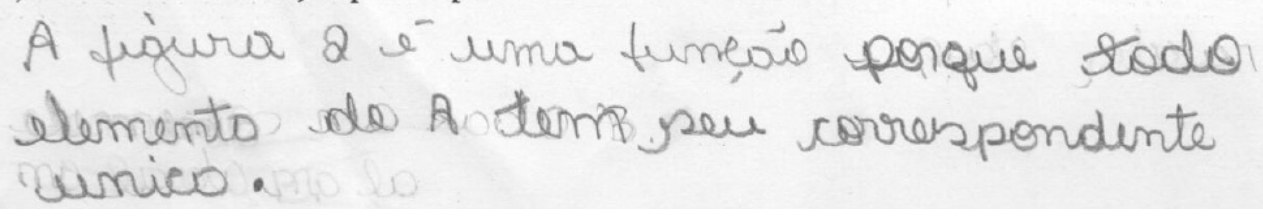

Fonte: Banco de dados dos autores

Podemos observar no primeiro retângulo da Figura 6 que o aluno A11, da primeira vez, respondeu de forma incorreta a Questão 1, pois afirmou ser função a relação que não era função e vice-versa. No segundo retângulo, ao observar as respostas erradas de seus colegas, ele conseguiu reconhecer alguns erros: ao escrever "não é conjunto é função" ele sugere a substituição do termo "conjunto" por "função", mas não fez referência ao uso inadequado do termo "domínio" no lugar de "elementos do domínio". Destacou, também, os erros da segunda afirmação, ao informar que a "figura 2 é uma função" e que "pode sobrar elementos no lado B". Na sua nova resolução da Questão 1, presente no terceiro retângulo, evidencia seu aprendizado ao modificar a afirmação dada na tarefa T1, ao perceber agora que "a figura 2 é uma função porque todo elemento de A tem seu correspondente único". No entanto, o aluno não reescreveu sua afirmação para o caso da relação da Figura 1, que não é função.

O estudante A13 deu as seguintes respostas:

Figura 7 - Respostas do aluno A13 nas tarefas T1 e T2.

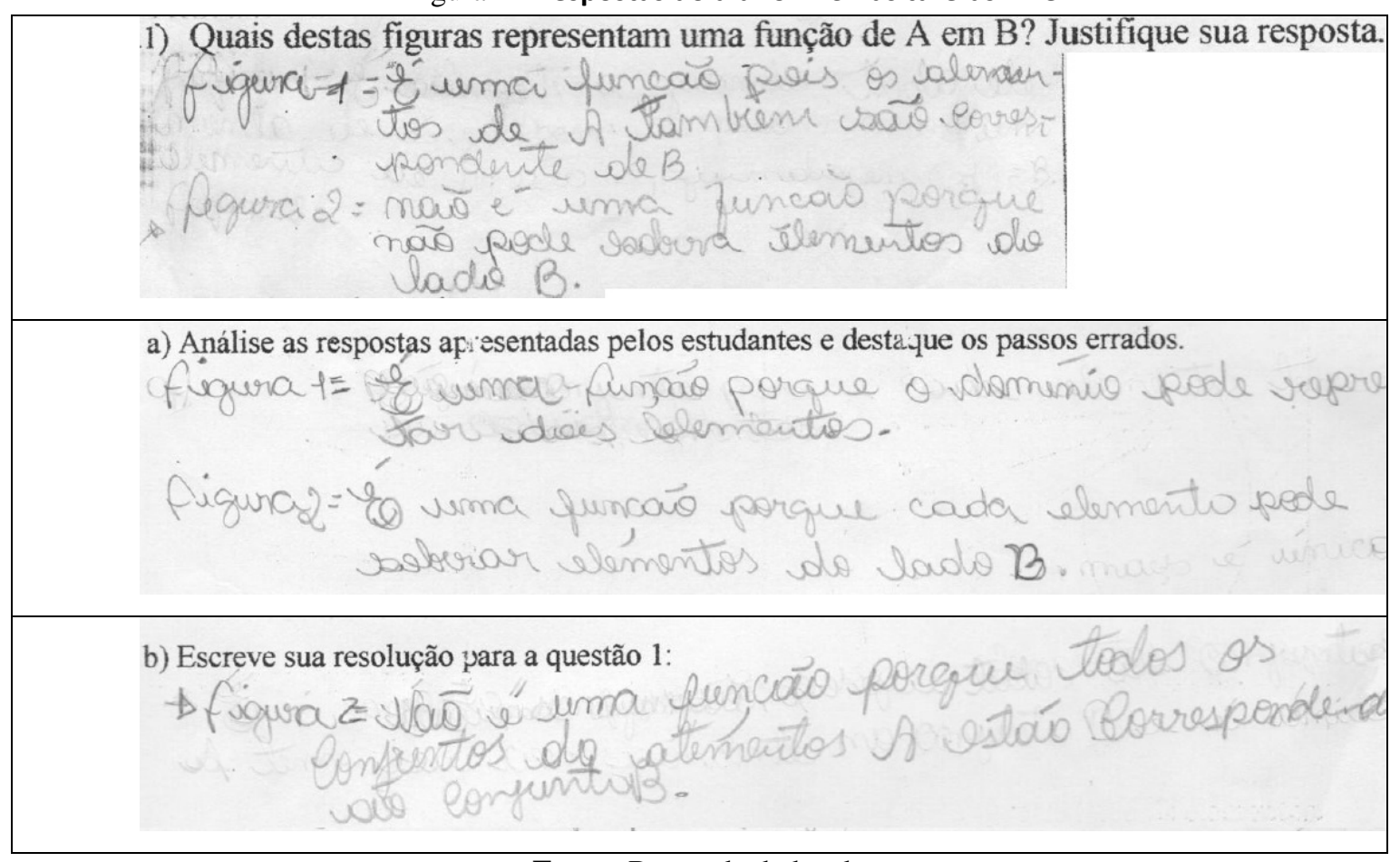

Fonte: Banco de dados dos autores 
Observamos no primeiro retângulo da Figura 7 que o aluno A13 quando fez a Questão 1 pela primeira vez a respondeu de forma incorreta. Ele não conseguiu identificar qual relação corresponde a uma função e qual não corresponde. No segundo retângulo podemos observar que ele classificou corretamente como função a segunda relação, mas identificou incorretamente a primeira relação como função, justificando com uma afirmação falsa "o domínio pode representar dois elementos" que também conserva o erro da utilização do termo "domínio" no lugar de "elemento do domínio". No terceiro retângulo está a nova resolução dele para a Questão 1. Apesar de no item "a" ele ter dito que as duas relações eram funções, no item "b" ele só se refere a uma dessas relações e afirma que "a figura 2 não é uma função porque todos os conjuntos dos elementos A estão correspondendo ao conjunto B". Observamos que o aluno classifica incorretamente a relação apresentada na Figura 2 como não sendo função. Além disso, podemos observar que utiliza "todos os conjuntos dos elementos A" querendo se expressar como "todos os elementos do conjunto A", mas não destaca o fato da correspondência ser única, isto é, cada elemento de A tem correspondente em B, mas apenas um correspondente. E, talvez por ter considerado que já havia respondido corretamente a primeira relação no item "a", não retomou essa resposta no item "b".

Este segundo grupo de alunos demonstrou dificuldades claras com relação ao conceito de função e à expressão correta da linguagem matemática. Na tarefa T2 ou continuaram classificando incorretamente as relações como função ou não, ou se classificaram de modo correto, não apresentaram justificativas adequadas. Além disso, a expressão textual continuou bastante confusa.

\section{ALGUMAS CONSIDERAÇÕES}

A produção escrita dos estudantes do $1^{\circ}$ ano do Ensino Médio do Professor P1 na resolução de exercícios envolvendo o conceito de Função e na análise dos erros dos colegas revela que poucos estudantes conseguiram destacar os erros dos colegas e que alguns deles reconhecem que em uma função todo elemento do domínio têm correspondente no contradomínio, e este é único. Entretanto, ainda não conseguiram se apropriar desse conceito, pois lhes faltam argumentos para justificar porque alguma relação não é função. Além disso, os dados também sinalizam que esses discentes apresentam dificuldades na expressão correta da linguagem matemática presente no 
conceito de função, pois trocam os nomes de alguns termos.

O trabalho desenvolvido permitiu perceber que a possibilidade de utilizar a análise de erros como metodologia de ensino apresentou alguns pontos que merecem destaque, tais como: a importância da retomada do conteúdo por meio da utilização de outras atividades, a contribuição da avaliação imediata e contínua do desempenho dos estudantes, e a oportunidade dos discentes refletirem sobre seus erros a partir dos erros de seus colegas.

Fazer com que o aluno possa ter outra chance com aquele conteúdo que ainda não compreendeu é um ponto chave. Principalmente porque a ênfase do ensino deixa de ser a quantidade de conteúdo que deve ser ensinada e passa a ser a qualidade de aprendizagem dos alunos quanto ao conteúdo ensinado. Mudando tal ênfase, o professor pode concentrar suas aulas na qualidade ao invés de priorizar a quantidade de informações. Podemos perceber que uma informação que, em geral, é ensinada em alguns minutos pelo professor, como a definição de função, acabou necessitando de quatro períodos de aula para começar a ser assimilada pelos discentes. Não queremos afirmar com isso que o conteúdo não deve ser dado por completo. Apenas que um conteúdo ensinado que não tenha sido bem assimilado pelo aluno acaba gerando "ruídos de aprendizagem" que se propagam aos demais tópicos do conteúdo. Dentro desse ponto de retomada, o professor pode ajustar a linguagem utilizada pelos alunos e tentar corrigi-la para os padrões adequados, tanto da correção da língua materna quanto do rigor matemático.

Além disso, tal metodologia requer que o professor realize avaliações imediatas e contínuas, tendo em vista que os erros apresentados pelos alunos numa tarefa acabam gerando material de análise para uma nova tarefa de realimentação. Isso é positivo também para os alunos, que já são avaliados a cada tarefa realizada, e não apenas nas provas do final da unidade. Além de que oportunizam que o professor acompanhe o processo de aprendizado de seus alunos.

No que se refere às tarefas que solicitam que o estudante identifique e analise erros de outros estudantes, vale salientar que essas atividades trabalham um aspecto que é ainda mais difícil do que o próprio conteúdo. De fato, o discente deve analisar o erro cometido por um aluno que está no mesmo estágio escolar dele e sobre o conteúdo que ele ainda não sabe se aprendeu. Dessa forma, o erro apresentado para análise ao aluno pode ser igual ou não ao dele. Assim, ele acabará sendo exigido a pensar num modo 
diferente do que pensou inicialmente. Isso deve ser previsto e avaliado pelo professor antes da proposição das tarefas.

Diante dos resultados encontrados no trabalho realizado por esse professor e seu grupo de alunos, é possível afirmar que o uso da metodologia de análise de erros como metodologia de ensino pode oportunizar situações de aprendizagem em sala de aula. Contudo, o uso dessa metodologia demanda tempo por parte do professor para realização da avaliação contínua dos alunos, dando ênfase na qualidade da aprendizagem do conteúdo. Além disso, é importante que o professor tenha bastante cuidado na elaboração das atividades que envolvem erros de outros estudantes de modo que a dificuldade da análise dos erros não seja superior à dificuldade do conteúdo em si.

\section{REFERÊNCIAS}

AZEVEDO, D. S. Análise de erros matemáticos: interpretação das respostas dos alunos. Trabalho de conclusão de Curso. Universidade Federal do Rio Grande do Sul Instituto de Matemática, Porto Alegre, 2009.

BOGDAN, R. C.; BIKLEN, S. K. Investigação qualitativa em educação: uma introdução à teoria e aos métodos. Portugal: Porto Editora, 1994.

BORASI, R. Reconceiving mathematics Instruction: a Focus on Errors. Norwood, NJ: Ablex Publishing Corporation, 1996.

CURY, H. N. Análise de Erros: o que podemos aprender com a resposta dos alunos. Belo Horizonte: Autêntica, 2008.

PINTO, N. B. O erro como estratégia didática: estudo do erro no ensino da Matemática Elementar. Campinas: Papirus, 2000.

SILVA, M. C. N.; BURIASCO, R.L.C. Análise da produção escrita em matemática: algumas considerações. Ciência \& Educação, v. 11, n. 3, p. 499-512, 2005. Disponível em http://www.scielo.br/pdf/ciedu/v11n3/11.pdf. Acesso em 23 Jul. 2015.

SOUZA, N. T. B. Análise de erros em funções matemáticas com alunos do $1^{\circ}$ Ano do Ensino Médio de Escola Pública, 2009. Disponível em http://www.ucb.br/sites/100/103/tcc/22009/nayaratavaresdebritosouza.pdf. Acesso em 20 Mar. 2015. 